RASĀYAN J. Chem.

Vol. 10 | No. 2 | 499 - 506 | April - June | 2017

ISSN: 0974-1496 | e-ISSN: 0976-0083 | CODEN: RJCABP

http://www.rasayanjournal.com

http://www.rasayanjournal.co.in

\title{
TECHNIQUES FOR ENVIRONMENTAL RISK ASSESSMENT: A REVIEW
}

\author{
Tejaswi D and Christopher Samuel ${ }^{*}$ \\ Department of Civil Engineering, SRM University, Kattankulathur, \\ Kancheepuram-603203, Tamil Nadu, India \\ *E-mail: christophersamuel.g@ktr.srmuniv.ac.in
}

\begin{abstract}
Environmental Risk Assessment (ERA) is a decision-making tool that enables affirmative actions, which lead to a safer environment, optimization of manufacturing processes, reduced business risks, and enhanced profitability. It makes an organization proactive and go beyond the paradigm of compliance to enable sustainability. A wide range of techniques are available in the literature, which can be employed in ERA. In this paper, a review of nine major techniques is presented. These techniques are Leopold matrix, Hazard and Operability study (HAZOP), Knowledgebased HAZOP, Fault Tree Analysis (FTA), Event Tree Analysis (ETA), Process mapping, Failure Mode and Effect Analysis (FMEA), What-if analysis, and Checklists. An outline of the origin, history, evolution, applications, and limitations of these techniques is provided. These techniques help in anticipating environmental hazards and implementing an effective environmental management plan.

Keywords: Environmental Risk Assessment, Leopold matrix, HAZOP, Knowledge-based HAZOP, Fault Tree Analysis, Event Tree Analysis, Process mapping, Failure Mode and Effect Analysis, What-if analysis, Checklists.

(C) RASĀYAN. All rights reserved
\end{abstract}

\section{INTRODUCTION}

Risk is the possible occurrence of an undesired outcome. Cardenas defines risk as "the likelihood that a harmful consequence will occur as the result of an action or condition. It involves the combined evaluation of hazards and exposure."1 There are many types of risk assessment (RA): Health RA, Environmental RA, Ecological RA, Disaster RA, etc.

Environmental Risk Assessment (ERA) is defined as- "an estimate of the likelihood or probability of an adverse impact on the environment resulting from human activities. (i.e., a formal procedure for identifying and estimating the risk of environmental damage)." ${ }^{2}$ It has become an integral part of the planning phase of various projects, particularly those involving manufacturing. It provides insights on the environmental concerns encountered by various organizations. It leads to an understanding of the likely adverse impacts and the risks imposed on the environment caused by various operations of an organization. It helps in choosing appropriate technologies, site selection, and implementing preventive measures. Even during the construction and operational phases of the projects, ERA provides vital information that reduces risks and costs. Looking beyond compliance, an organization can use the framework of ERA for ensuring sustainable development.

ERA is a prerequisite for enabling an organization to prepare and implement a suitable environmental management plan that mitigates or eliminates environmental risks. Thus, ERA is applied in various industries, such as, mining, ${ }^{3}$ agriculture, ${ }^{4,5}$ airlines, ${ }^{6}$ construction, ${ }^{7}$ and especially in the pharmaceutical industry. ${ }^{8,910,11}$ In this paper, the various approaches toward ERA are outlined and discussed.

\section{TECHNIQUES FOR ENVIRONMENTAL RISK ASSESSMENT}

\section{Leopold matrix}

In 1971, Leopold ${ }^{12}$ designed a matrix to evaluate the environmental impacts. This matrix consists of columns representing organizational actions, such as, mineral processing, trucking, blasting, and drilling and rows representing environmental elements, such as, water quality and atmospheric quality. He also

Rasayan J. Chem., 10(2), 499 - 506(2017)

http://dx.doi.org/10.7324/RJC.2017.1021657 
provided scope for scoring the magnitude and importance of the identified impacts on a scale of 1 to 10 . Josimovic et al. ${ }^{13}$ used this technique for carrying out environmental impact assessment for wind farms in Serbia. Jiang et al. ${ }^{14}$ improvised Leopold matrix and developed an environmental performance assessment method for manufacturing process plans.

Further, Leopold matrix can be applied for ERA as well. The matrix is constructed with rows representing environmental aspects, such as, discharges to water bodies, and emissions to air and columns representing various organizational activities. The cells corresponding to each activity are checked against the plausible aspects. Each aspect is scored based on the number of checks. The highest of these scores is considered the reference value. All aspects with a score greater than $50 \%$ of the reference value are considered significant and ranked accordingly. Based on these, the overall environmental risk is assessed. Darbra et al. ${ }^{15}$ addressed this approach as a procedure for identifying and ranking significant environmental aspects.

However, the Leopold matrix and its variations have the following limitations:

- Leopold matrix can be unmanageable as the size of the matrix increases. ${ }^{16}$

- It lacks provision for scoring the aspects that may result from multiple or series of activities.

- The scoring of magnitude and importance on a scale of 1 to 10 , is purely based on the assessor's perception, and therefore, is subjective. A wide variety of scores can be arrived at from different experts.

- An expert's assessment cannot be easily understood by another user. The user will not be able to grasp the scoring without an explanation.

\section{Hazard and Operability study}

Hazard and Operability study (HAZOP) is a Process Hazard Analysis (PHA) technique that enables an understanding of hazards and operability problems in a system. The word, HAZOP, was coined by Kletz in 1984. ${ }^{17}$ However, Kletz and his team developed the first detailed design of operability studies in the early 1960s. In 1974, the first paper on operability studies and hazard analysis was published by Lawley. ${ }^{18}$ Three years later, in 1977, a formal guide to Hazard and Operability studies was introduced by the Chemical Industries Association. ${ }^{19} 20$ years later, in 1999, Kletz's paper on the detailed process of identifying and assessing process industry hazards was published. ${ }^{20}$ HAZOP has gained further widespread appreciation since the time Kletz published his experiences in designing and practicing it for the prevention of accidents and protection of personnel and equipment. . $^{21,22}$

Ever since HAZOP gained recognition, it has been applied in various research areas, such as, medical diagnostic systems, ${ }^{23}$ road-safety measures, ${ }^{24}$ and hazard analysis for photovoltaic facilities. ${ }^{25}$ Even in environmental related research, HAZOP is used for assessing various environmental risks ${ }^{26,}{ }^{27,}{ }^{28}$ From the perspective of the environment, HAZOP is considered as a systematic method for identifying potential sources of emissions. ${ }^{29}$ Dunjo et al. ${ }^{30}$ provided a comprehensive review of literature on HAZOP.

As a first step, in HAZOP, process stages are clearly outlined. For each process stage, relevant parameters, such as, temperature, composition, level, head, and pressure are identified. For each parameter, guide-words like more, less, reverse, impurities, higher, etc., are applied to generate deviations from the existing scenario. The possible causes for each deviation are understood and the probable consequences are analysed. Necessary actions to be taken to restore the process to the designer's intentions are also identified. A structured table containing every identified parameter with its deviations, their possible causes and consequences, and the actions that are required to be taken is developed. This is repeated for every process stage.

The limitations of HAZOP are as follows:

- HAZOP focuses on single events. It does not consider possible combinations of events.

- The HAZOP's focus on guide-words may lead to overlooking some risks that are not related to a guide-word.

- HAZOPs are time consuming and expensive.

- It depends on the knowledge and skill levels of the participant. 


\section{Knowledge-based HAZOP}

Knowledge-based HAZOP is a refined approach when compared with HAZOP. Here, the knowledge gained by the company from past experiences is used rather than depending on forecasting. Identification of parameters is based on processes and is similar to that of in HAZOP. However, the guide-words like more, less, reverse, impurities, higher, etc., are modified based on the knowledge gained by the company from its past experiences. A structured table is developed for every identified parameter with its deviations, their possible causes and consequences, and the actions that are required to be taken.

Knowledge-based HAZOP leads to better control and provides scope for automation. ${ }^{31}$ The limitations of this approach are as follows:

- It cannot be applied for the first ERA, as it lacks knowledge from the past.

- It depends on accuracy of historical data.

\section{Fault Tree Analysis}

Fault Tree Analysis (FTA) is a deductive approach for resolving an undesired event (risk) back to its causes. It can be effectively applied to risk assessment and accident-incident analysis. FTA was developed by $\mathrm{H}$. Watson and A. Mearns of Bell Laboratories in 1961 to evaluate the Minuteman Launch Control System. ${ }^{32}$ FTA is the conversion of the failure behaviour of a physical system into a visual form (logic diagram). The first step is to identify the risks or undesired events. Each identified event is resolved back to its immediate and basic causes. A logic diagram (fault tree) is constructed using logic symbols to depict the relationships between these events and causes. The constructed fault tree is then evaluated to quantify the failure probability. Addition, multiplication, algebraic functions, and Boolean functions aid the calculation of these probabilities. An action plan is developed to reduce the occurrence of these identified risks.

Fussel $^{33}$ explained a formal methodology for the construction of fault trees. Singer ${ }^{34}$ provided a fuzzy set approach to FTA. Ericson ${ }^{32}$ discussed the wide-ranging applications, major improvements, and various trends of FTA. Lee et al. ${ }^{35}$ reviewed and classified the FTA methods developed from the 1960s to 1980s. They classified the literature based on definition of the system, construction of the fault trees, type of evaluation, and the available computer codes for FTA. FTA has been widely used in environmental applications, such as, risk analysis of drinking water systems, ${ }^{36}$ probability assessment of contaminantdischarge from shipwrecks, ${ }^{37}$ and analysis of pollution caused by vehicular emissions. ${ }^{38}$

In brief, FTA identifies weaknesses in the system and the causes of a failure, assesses proposed design for safety and reliability, quantifies the failure probability, optimizes the management actions. However, demerits of the Fault Tree Analysis are as follows:

- FTA can embroil complex mathematics.

- Human errors can either undervalue or overvalue risks.

- It depends on specialist knowledge.

\section{Event Tree Analysis}

The evolution of event trees was necessitated as fault trees were often too large and complicated to compute. Event Tree Analysis (ETA), also known as the pipeline risk assessment method, was developed in 1974 for the safety study of the WASH-1400 nuclear power plant in the USA. ${ }^{39}$

While FTA is a deductive approach, ETA is an inductive approach as it induces the consequences of an undesired event rather than deducing the causes for it (like in FTA). ETA analyses the effects of system failure supposing an undesired event has occurred..$^{40}$ The first step in ETA is to identify the initiating-events, such as, equipment failure and process malfunction. A logic diagram (event tree) is generated, beginning with an initiating-event and developing the possible sequence of events, which may lead to potential accidents. The probability of each identified initiating-events that lead to a potential accident is evaluated by simple addition and multiplication of the probabilities of the sequential events. A management plan is developed with corrective actions to mitigate the risk associated with the undesired events.

Huang et al. ${ }^{41}$ discussed a fuzzy set approach to ETA. Ferdous et al. ${ }^{42}$ explained how fuzzy sets and evidence theory can be used while performing an ETA for handling data uncertainties, such as, imprecision, 
inconsistency, and subjectivity. Shi et al. ${ }^{43}$ explained how ETA can be used to create 54 different scenarios for chemical pollution accidents. Peila and Guardini ${ }^{44}$ used ETA for the evaluation of the collective risk of rockfall. Neri et al. ${ }^{45}$ conducted a probabilistic hazard assessment of volcanic eruption.

ETA has the following limitations:

- It cannot be applied for complex processes.

- Accurate identification of initiating-events is a precursor for this analysis. Unidentified initiatingevents could lead to misleading results.

\section{Process mapping}

Process mapping is a workflow diagram to understand a process or a series of parallel processes, such as, manufacturing processes and treatment processes. The structured method for documenting process-flow was pioneered by Frank Gilbreth in the 1920s. ${ }^{46}$ A process approach is recommended by ISO 9001: 2015 as it enables an organization to plan its processes and their interactions ${ }^{47}$ Process mapping is an essential tool used for the implementation of environmental management systems according to ISO 14001: $2015 .^{48}$ Process mapping can be applied to ERA too as it enables visualization and documentation of processes. Process mapping is versatile as it can be effectively used in conjunction with other techniques.

The first step in process mapping is to identify the interconnected processes followed by collecting information on the steps involved in each of them. The next step is to generate a map from the collected information that identifies the activities that may lead to significant environmental aspects. Plausible impacts resulting from these identified aspects are predicted and a risk reduction plan is developed for implementation in the organization. Thus, a process map is not just a flow diagram that depicts the flow of materials or processes, but a tool that illustrates the flow of information needed to manage the organization. In 1998, Lin and Polenske ${ }^{49}$ developed a micro-level input-output process model (IOPM) that provides a mathematical description of processes and explained its use in process analysis, structural analysis, and environmental management. Polenske and McMichael $^{50}$ modified the IOPM developed by Lin and Polenske ${ }^{49}$ and designed an energy process-flow model for conducting energy and environmental analyses of coke making in China.

Damelio $^{51}$ provided a comprehensive description of process mapping. Anjard ${ }^{52}$ explained how process mapping can be used as a tool for management, quality, and other professionals. $\operatorname{Rath}^{53}$ used process mapping as a tool for developing a quality management program. Huntzinger and Eatmon ${ }^{54}$ used process mapping as a tool for conducting a cradle-to-gate life-cycle assessment to evaluate the environmental impacts of different cement manufacturing processes. Suh and Huppes ${ }^{55}$ performed life-cycle inventory analysis of a product using process-flow diagrams.

The limitations of this approach are as follows:

- With increased detail of process mapping, analysis and usefulness can become complex.

- Data can imbibe bias owing to employee experiences.

- It requires skill and painstaking effort. Hastiness can lead to erroneous conclusions.

\section{What-if analysis}

What-if analysis is another technique of hazard analysis. It is advantageous during the design and operating phases of a project. Unlike HAZOP and FTA, it does not require extensive preplanning. It utilizes information related to processes, operations, operating procedures, and operating conditions to frame several what-if questions. These questions address the issues related to start up, shutdown, equipment failure, process upsets and feed upsets due to temperature and pressure, accidents related to handling and maintenance, and other causes. Once the questions are framed, the probable consequences for each what-if question (if at all, it happens) are obtained through brainstorming and forecasting. This forecasting mainly focuses on the consequences that result in production downtime or economic loss and consequences that affect the workforce on-site, off-site population, and environment. The results of this analysis include the what-if questions, the hazards associated with each of them, their relative ranks, and the actions required to be taken to mitigate risks. 
Hiremath et al. ${ }^{56}$ employed what-if analysis to articulate the health, safety, and environmental issues associated with recycling of ships in India, and based on which, they conducted risk assessment and developed a ship-specific recycling plan. Reniers et al. ${ }^{57}$ combined what-if analysis, HAZOP, and the risk matrix and developed an integrated framework (Hazwim) for risk evaluation.

What-if analysis has the following limitations:

- It is a speculative method that is based on likely scenarios of undesired events.

- It is qualitative and ranking is not based on numerical analysis.

- It relies on team experience, intuition, imagination, and forecasting; unpredicted consequences and human errors can lead to unaddressed risks.

\section{Failure Mode and Effect Analysis}

Failure Mode and Effect Analysis (FMEA) is a quality analysis technique that evaluates the design of a system and its associated processes for possible ways in which failures can occur. It focuses on reliability indices and failure modes, such as, equipment failure, incorrect operations, mechanical repairs, and shutdowns. These failures are assessed based on their occurrence, severity, and detection and the risk priority numbers (RPN) are calculated. In ERA, FMEA can be applied to identify likely failures.

FMEA was used for the design of flight control systems in early $1950 \mathrm{~s}^{58}$ Stamatis $^{59}$ provided a detailed explanation of FMEA and its execution. Liu et al. ${ }^{60}$ reviewed 75 articles on FMEA which were published between 1992 and 2012 and categorized them based on the risk evaluation approaches. FMEA has been widely used in environmental applications, such as, risk analysis of sewage treatment plants, ${ }^{61}$ risk analysis of supercritical water gasification used in sewage-sludge treatment process, ${ }^{62}$ assessment of water treatment plants, ${ }^{63}$ and hazard analysis of a waste-to-energy process (biomass combustion). ${ }^{64}$

Limitations of FMEA are as follows:

- FMEA can fail if all the hazards are not identified.

- Assigning numbers to severity and occurrence of failures is subjective, therefore, an analysis from different assessors may yield different risk priority numbers for the same process.

- It prioritizes and ranks the failure modes, however, it does not provide for a management plan.

\section{Checklists}

Checklists play a crucial role in many approaches that lead their way to ERA. A checklist can by itself serve as a technique for ERA or be a part of other techniques. In fact, the Leopold matrix is a bi-dimensional checklist. A checklist contains a set of pre-defined evaluation criteria. Simple checklists address a list of factors, whereas, descriptive checklists can address actions, their impacts, their ranks, mitigation plan, etc. Checklists enable the identification of components of a plant that require safe design and help designers to address the identified hazards. This technique uses data from the past experiences and relies on expert judgment.

The USDA ${ }^{65}$ developed a comprehensive checklist for environmental impact assessment of proposed projects, which provides an analytical framework to evaluate potential environmental risks prior to the implementation of the projects. Agerstrand et al. ${ }^{66}$ conducted a structured evaluation of ecotoxicity-based environmental risk assessment using checklists. Fedra ${ }^{67}$ developed an adaptive hierarchical checklist to evaluate the environmental risks of river development projects. Snell and Cowell ${ }^{68}$ provided a critique of checklists in scoping for environmental impact assessment.

Limitations of checklists are as follows:

- Checklists may not be robust without extensive past experiences and past failure records.

- The appropriateness of a checklist relies on several factors that were applicable at the time of its; if they differ, the checklist will be outdated, inapplicable, and misleading.

- It requires periodical reviews and frequent updates.

Based on the usefulness of each technique described above, a summary of their applications is provided in 
Table-1. The usefulness of each technique is rated on a scale of 0 to 5 , where 5 indicates the most appropriate technique for the corresponding area of application.

Table-1: Ranking of ERA techniques based on their appropriateness in different areas of application

\begin{tabular}{c|c|c|c|c|c|c}
\hline & Manufacturing & $\begin{array}{c}\text { Natural } \\
\text { Hazards }\end{array}$ & Processing & $\begin{array}{c}\text { Ecological } \\
\text { receptors }\end{array}$ & $\begin{array}{c}\text { Pre-project } \\
\text { (construction) } \\
\text { stage }\end{array}$ & $\begin{array}{c}\text { Post-project } \\
\text { (operational) } \\
\text { stage }\end{array}$ \\
\hline Leopold matrix & 1 & 5 & 1 & 5 & 3 & 3 \\
\hline HAZOP & 5 & 1 & 5 & 1 & 2 & 4 \\
\hline $\begin{array}{c}\text { Knowledge- } \\
\text { based HAZOP }\end{array}$ & 5 & 1 & 5 & 1 & 5 & 4 \\
\hline FTA & 4 & 0 & 4 & 0 & 1 & 4 \\
\hline ETA & 4 & 0 & 4 & 0 & 2 & 4 \\
\hline $\begin{array}{c}\text { Process } \\
\text { mapping }\end{array}$ & 4 & 1 & 4 & 2 & 2 & 5 \\
\hline FMEA & 5 & 0 & 5 & 0 & 1 & 5 \\
\hline $\begin{array}{c}\text { What-if } \\
\text { Analysis }\end{array}$ & 3 & 3 & 3 & 2 & 5 & 4 \\
\hline Checklists & 3 & 3 & 3 & 4 & 5 & 3 \\
\hline
\end{tabular}

\section{CONCLUSION}

ERA is an essential tool for appropriate environmental planning and management, particularly, for industries that have likely impacts on various environmental components. It helps an organization to be proactive and go beyond the paradigm of compliance to enable sustainability. It requires the employment of sophisticated techniques that are relevant with rigor. Though there is no universal mechanism that can be adopted, specific protocols need to be adopted based on the nature of operations. This work provides a comprehensive review of important techniques available in the literature. The import, evolution, applications, and limitations of these techniques are presented in the above sections. These techniques help in anticipating and preventing environmental hazards. It should be emphasized that one or a combination of more than one of these techniques can be gainfully employed for ERA.

\section{REFERENCES}

1. http://www.unep.or.jp/ietc/publications/techpublications/techpub-14/1-EnRA1.asp

2. http://www.env.gov.bc.ca/wld/documents/era.pdf

3. O. Aslibekian and R. Moles, Environmental Geochemistry and Health, 25, 2 (2003)

4. T. E. Nickson, Plant Physiology, 147, 2 (2008)

5. A. Finizio and S. Villa, Environmental Impact Assessment Review, 22, 3 (2002)

6. Z. Chen, H. Li, H. Ren, Q. Xu and J. Hong, International Journal of Project Management, 29, 7 (2011)

7. A. H. El Sherbiny, A. H. Sherif and A. N. Hassan, Journal of Environmental Engineering, 132, 10 (2006)

8. R. Länge and D. Dietrich, Toxicology Letters, 131, (2002)

9. T. Backhaus and M. Faust, Environmental Science and Technology, 46, 5 (2012)

10. M. Rand-Weaver, L. Margiotta-Casaluci, A. Patel, G. H. Panter, S. F. Owen and J. P. Sumpter, Environmental Science and Technology, 47, 20 (2013)

11. M. Gros, M. Petrović, A. Ginebreda and D. Barceló, Environment International, 36, 1 (2010)

12. L. B. Leopold, A procedure for evaluating environmental impact, US Dept. of the Interior, 28, 2 (1971)

13. B. Josimovic, J. Petric and S. Milijic, Energy and Environment Research, 4, 1 (2014)

14. Z. Jiang, H. Zhang and J. W. Sutherland, The International Journal of Advanced Manufacturing Technology, 58, 5-8 (2012)

15. R. M. Darbra, A. Ronza, T. A. Stojanovic, C. Wooldridge and J. Casal, Marine Pollution Bulletin, 50, 8 (2005) 
RASĀYAN J. Chem.

Vol. 10 | No. 2 |499 - 506 | April - June | 2017

16. C. S. Holling, Adaptive Environmental Assessment and Management, John Wiley \& Sons, (1978)

17. T. A. Kletz, HAZOP and Hazan - Notes on the Identification and Assessment of Hazards, IChemE (LP), Rugby (1984)

18. H. G. Lawley, Chemical Engineering Progress, 70, 4 (1974)

19. Imperial Chemical Industries, Itd, Chemical Industries Association. Chemical Industry Safety, \& Health Council. (1977). A Guide to Hazard and Operability Studies. Chemical Industry Safety and Health Council of the Chemical Industries Association.

20. T. A. Kletz, HAZOP and HAZAN: Identifying and Assessing Process Industry Hazards. IChemE, (1999)

21. T. A. Kletz, By Accident: A Life Preventing Them in Industry, IChemE, (2000)

22. T. A. Kletz, Learning from Accidents, Routledge, (2001)

23. M. F. Chudleigh, Computer Methods and Programs in Biomedicine, 44, 1 (1994)

24. H. M. Jagtman, A. R. Hale and T. Heijer, Reliability Engineering and System Safety, 90, 2(2005)

25. V. M. Fthenakis, S. R. Trammell, Reference Guide for Hazard Analysis in PV Facilities, Brookhaven National Laboratory draft report, Upton, NY, (2003)

26. B. S. Sinanan, F. P. Khan, R. Jokhoo, F. Innis and V. Ramlogan, In SPE International Improved Oil Recovery Conference in Asia Pacific. Society of Petroleum Engineers, Kuala Lumpur, Malaysia (2005)

27. I. Mohammadfam, A. Sajedi, S. Mahmoudi and F. Mohammadfam, International Journal of Occupational Hygiene, 4, 2 (2015)

28. M. A. de la O Herrera, A. S. Luna, A. C. A. da Costa and E. M. B. Lemes, Journal of Loss Prevention in the Process Industries, 35 (2015)

29. T. R. Knepper, Pollution Engineering, 26, 3 (1994)

30. J. Dunjó, V. Fthenakis, J. A. Vílchez and J. Arnaldos, Journal of Hazardous Materials, 173, 1 (2010)

31. V. Venkatasubramanian and R. Vaidhyanathan, AIChE Journal, 40, 3 (1994)

32. C. A. Ericson, In Proceedings of the 17th International System Safety Conference, Orlando, Florida (1999)

33. J. B. Fussell, Nuclear Science and Engineering, 52, 4 (1973)

34. D. Singer, Fuzzy Sets and Systems, 34, 2 (1990)

35. W. S. Lee, D. L. Grosh, F. A. Tillman and C. H. Lie, IEEE Transactions on Reliability, 34, 3 (1985)

36. A. Lindhe, L. Rosén, T. Norberg and O. Bergstedt, Water Research, 43, 6 (2009)

37. H. Landquist, L. Rosén, A. Lindhe, T. Norberg, I. M. Hassellöv, J. F. Lindgren and I. Dahllöf, Marine Pollution Bulletin, 88, 1 (2014)

38. W. Huang, H. Fan, Y. Qiu, Z. Cheng, P. Xu and Y. Qian, Chemosphere, 151 (2016)

39. P. L. Clemens, R. J. Simmons, and O. Cincinnati, System safety and risk management: A guide for engineering educators. NIOSH Instruction module. CDC, US Dept. Health and Human Services VIII$1-$ VIII-8 (1998)

40. J. X. Wang and M. L. Roush, What every engineer should know about risk engineering and management, CRC Press (2000)

41. D. Huang, T. Chen and M. J. J. Wang, Fuzzy Sets and Systems, 118, 1 (2001)

42. R. Ferdous, F. Khan, R. Sadiq, P. Amyotte and B. Veitch, Process Safety and Environmental Protection, 87, 5 (2009)

43. S. Shi, J. Cao, L. Feng, W. Liang and L. Zhang, Journal of Hazardous Materials, 276 (2014)

44. D. Peila, and C. Guardini, Natural Hazards and Earth System Sciences, 8, 6 (2008)

45. A. Neri, W. P. Aspinall, R. Cioni, A. Bertagnini, P. J. Baxter, G. Zuccaro, D. Andronico, S. Barsotti, P. D. Cole, T. E. Ongaro, T. K. Hincks, G. Macedonio, P. Papale, M. Rosi, R. Santacroce and G. Woo, Journal of Volcanology and Geothermal Research, 178, 3 (2008)

46. F. Gilbreth and L. Gilbreth, The Quest of the One Best Way, Purdue University, Frank and Lillian Gilbreth Papers, (1924)

47. ISO 9001 Quality Management Systems — Requirements (2015)

48. ISO 14001 Environmental management systems — Requirements with Guidance for Use (2015)

49. X. Lin and K. R. Polenske, Structural Change and Economic Dynamics, 9, 2 (1998) 
RASĀYAN J. Chem.

Vol. 10 | No. 2 |499 - 506 | April - June | 2017

50. K. R. Polenske and F. C. McMichael, Energy Policy, 30, 10 (2002)

51. R. Damelio, The Basics of Process Mapping, CRC Press, (2011)

52. R. P. Anjard, Microelectronics Reliability, 36, 2 (1996)

53. F. Rath, International Journal of Radiation Oncology, Biology, Physics, 71, 1 (2008)

54. D. N. Huntzinger and T. D. Eatmon, Journal of Cleaner Production, 17, 7 (2009)

55. S. Suh, and G. Huppes, Journal of Cleaner Production, 13, 7 (2005)

56. A. M. Hiremath, S. K. Pandey and S. R. Asolekar, Journal of Cleaner Production, 116 (2016)

57. G. L. L. Reniers, W. Dullaert, B. J. M. Ale and K. Soudan, Journal of Loss Prevention in the Process Industries, 18, 3 (2005)

58. B. S. Dhillon, Microelectronics Reliability, 32, 5 (1992)

59. D. H. Stamatis, Failure mode and effect analysis: FMEA from theory to execution, ASQ Quality Press (2003)

60. H. C. Liu, L. Liu, and N. Liu, Expert Systems with Applications, 40, 2 (2013)

61. M. H. Hsieh, Masters' Thesis, Department of Industrial Management, National Taiwan University of Science and Technology (2005)

62. E. Adar, M. İnce, B. Karatop and M. S. Bilgili, Journal of Environmental Chemical Engineering, 5, 1 (2017)

63. T. Kučera, L. Tuhovčák and R. Biela, Procedia Engineering, 162 (2016)

64. P. X. Thivel, Y. Bultel and F. Delpech, Journal of Hazardous Materials, 151, 1 (2008)

65. U.S. Department of Agriculture, Checklist for summarizing the environmental impacts of proposed projects, Stillwater, Oklahoma Cooperative State Research Service (1990)

66. M. Ågerstrand, A. Küster, J. Bachmann, M. Breitholtz, I. Ebert, B. Rechenberg, and C. Ruden, Environmental Pollution, 159, 10 (2011)

67. K. Fedra, In Proceedings of the Workshop on Indicators and Indices for Environmental Assessment and Risk Analysis, pp. 11-40 (1990)

68. T. Snell and R. Cowell, Environmental Impact Assessment Review, 26, 4 (2006)

[RJC-1657/2017] 